\title{
Ground and excited state communication within a ruthenium containing benzimidazole metallopolymer
}

\author{
Emmet J. O’Reilly, Lynn Dennany* ${ }^{\dagger}$, Darren Griffith, Francois Moser, Tia E. Keyes, and Robert J. \\ Forster*
}

\author{
${ }_{5}$ Received (in $\left.X X X, X X X\right)$ Xth XXXXXXXXX 200X, Accepted Xth XXXXXXXXX 200X \\ First published on the web Xth $X X X X X X X X X 200 X$ \\ DOI: 10.1039/b000000x
}

Emission spectroscopy and electrochemistry has been used to probe the electronic communication between adjacent metal centres and the conjugated backbone within a family of imidazole based 10 metallopolymer, $\left[\mathrm{Ru}(\mathrm{bpy})_{2}(\mathrm{PPyBBIM})_{\mathrm{n}}\right]^{2+}$, in the ground and excited states, bpy is 2,2 '-bipyridyl, PPyBBIM is poly[2-(2-pyridyl)-bibenzimidazole] and $n=3,10$ or 20. Electronic communication in the excited state is not efficient and upon optical excitation dual emission is observed, i.e., both the polymer backbone and the metal centres emit. Coupling the ruthenium moiety to the imidazole backbone results in a red shift of approximately $50 \mathrm{~nm}$ in the emission spectrum. Luminescent

15 lifetimes of up to $120 \mathrm{~ns}$ were also recorded. Cyclic voltammetry was also utilized to illustrate the distance dependence of the electron hopping rates between adjacent metal centres with ground state communication reduced by up to an order of magnitude compared to previously reported results when the metal to backbone ratio was not altered. $\mathrm{D}_{\mathrm{CT}}$ and $\mathrm{D}_{\mathrm{e}}$ values of up to $3.96 \times 10^{-10}$ and $5.32 \times 10^{-10} \mathrm{~cm}^{2} \mathrm{~S}^{-1}$ were observed with corresponding conductivity values of up to $2.34 \times 10^{-8}$ ${ }_{20} \mathrm{Scm}^{-1}$.

\section{Introduction}

The extensive delocalization of $\pi$-electrons within electronically conducting polymers ${ }^{1,2,3}$ is well known to be responsible for a number of useful photonic properties 25 including non-linear optical behaviour, electronic conductivity, and exceptional mechanical properties. ${ }^{4,5}$ In particular, benzimidazole polymers are attractive since metal complexes can be coordinated to the polymer backbone opening up the possibility of site-to-site electron hopping as 30 well as electron transfer mediated by the polymer backbone itself. . $^{6,8,9,10,11,12}$

These conjugated metallopolymers are attracting increasing attention because of their potentially widespread applications, ${ }^{13,14,15,16,17,18}$ and significant attention has been ${ }_{35}$ paid to polymers containing poly(pyridyl) complexes of ruthenium(II) and osmium(II). ${ }^{19,20,21,22}$ These metal complexes confer attractive redox and photophysical properties on the polymer and different metal loadings can be prepared by simply varying the relative mole ratio of the reactants.

40 Moreover, since these materials can be readily dissolved, their properties can be examined in detail in solution as well as in thin films. ${ }^{23,24}$ Conventional spectroscopic and electrochemical methods can be used to probe the nature of the coordination sphere around the metal atom and also 45 investigate the ground and excited state properties of the polymer backbone.

Previous investigations into the electrochemical properties of ruthenium containing benzimidazole metallopolymers suggest that there is significant electronic communication 50 between adjacent metal centres in the ground state. ${ }^{6}$ This enhanced communication could be advantageous for sensor and molecular electronics applications, for example, the light intensity of electrochemiluminescence based sensors depend on the rate at which $\mathrm{Ru}^{3+}$ is regenerated electrochemically. ${ }^{25,26}$ 55 Moreover, from the perspective of excited state interactions, the extent of electronic communication between the luminescent polymer backbone and metal complexes will influence the emission properties. For example, where strong coupling occurs between only a single emission would be 60 expected from the lowest energy state, but the intensity could be enhanced due to the greater quantum efficiency across a wider wavelength range thereby leading to the development of sensors with lower limits of detection. ${ }^{27}$

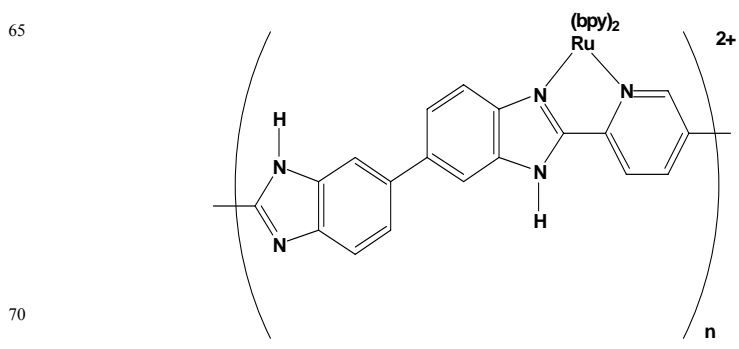

Scheme 1. Structure of $\left[\mathrm{Ru}(\mathrm{bpy})_{2}(\mathrm{PPyBBIM})_{\mathrm{n}}\right]^{2+}$.

In this contribution, the extent of electronic communication between adjacent ruthenium centres and between the ruthenium centres and polymer backbone is reported in both 75 the ground and electronically excited states. Scheme 1 illustrates the structure of the $\left[\mathrm{Ru}(\mathrm{bpy})_{2}(\mathrm{PPyBBIM})_{\mathrm{n}}\right]^{2+}$ metallopolymer, where $\mathrm{n}$ describes the number of monomer units separating each metal centre. The relative energies of the metal complexes and the polymer backbone as well as the 80 separation between the metal centres will influence the extent 
of electronic communication. Therefore, we have investigated the effect of changing the number of monomer units separating adjacent metal centres from 3 to 10 and 20 on the electrochemical and photophysical properties. Significantly, 5 emission is observed from both the polymer backbone and the ruthenium centres suggesting weak electronic communication in the excited state. In contrast, electrochemistry reveals that there is efficient communication between adjacent metal centres in the ground state. These results provide significant

10 new insights into the design of metallopolymers containing conjugated backbones for sensing applications ranging from electrochemical and photonic detection of nucleic acid and proteins to electroluminescent display devices.

\section{Experimental Section}

\section{Materials and Reagents}

The metallopolymers, $\left[\mathrm{Ru}(\mathrm{bpy})_{2}(\mathrm{PPyBBIM})_{\mathrm{n}}\right]^{2+}$, where $\mathrm{n}$ is 3,10 or 20, were prepared as described previously. ${ }^{4,6}$ For electrochemical measurements $\mathrm{LiClO}_{4}$ purchased from Sigma Aldrich was used as the supporting electrolyte and made up to 20 volume with MilliQ water $(18 \mathrm{M} \Omega \mathrm{cm})$. All solvents used were of spectroscopic grade and were stored over activated 4A molecular sieves.

\section{Apparatus}

Photoluminescence was recorded using a Perkin Elmer LS-50 25 luminescence spectrometer. Samples were prepared at concentrations of $10^{-4}$ to $10^{-5} \mathrm{M}$ in spectroscopic grade acetonitrile and all spectroscopic measurements were carried out using $1 \mathrm{~cm}$ quartz cuvettes. Electrochemical experiments were performed in a standard electrochemical cell using a $\mathrm{CH}$ 30 instruments (Memphis TN.) model 440 potentiostat. Cyclic voltammetry experiments were carried out using a $3 \mathrm{~mm}$ diameter glassy carbon working electrode in a conventional three electrode assembly using a platinum flag as the counter electrode. Working electrodes were cleaned by polishing with 35 alumina $(1.0 \mu \mathrm{m}-0.3 \mu \mathrm{m})$ on a felt pad, followed by sonication in distilled deionized water for $30 \mathrm{~min}$. Where appropriate, working electrodes were modified by applying a drop $(\approx 15 \mu \mathrm{L})$ of an ethanolic solution of the metallopolymer to the electrode surface. The modified electrodes were then 40 allowed to dry in the dark for 10 to 12 hours. The surface coverage, $\Gamma$, was determined by graphical integration of background corrected cyclic voltammograms $\left(<5 \mathrm{mV} \mathrm{s}^{-1}\right)$. In all cases, the surface coverage ranged from 1.4 to $3.1 \times 10^{-8}$ mol cm$~^{-2}$. Potentials were measured versus a standard ${ }_{45} \mathrm{Ag} / \mathrm{AgCl}$ aqueous reference electrode. All electrochemical measurements were carried out in $0.1 \mathrm{M} \mathrm{LiClO}_{4}$ which had been adjusted to $\mathrm{pH}$ 6. All solutions were deoxygenated using nitrogen or argon prior to measurement. Interdigitated Array Electrodes (IDA) were purchased from Abtech, $25 \mu \mathrm{M} \times 10$ ${ }_{50} \mu \mathrm{M}$ finger size with $10 \mu \mathrm{M}$ separation, and modified by drop casting polymer films $(\sim 40 \mu 1)$ as described above.

Luminescent lifetimes were measured using the third harmonic (355 nm) of a Spectron Q-switched Na-Yag laser for excitation. Emission was detected in a right-angled
55 configuration to the laser using an Oriel model IS520 gated intensified CCD coupled to an Oriel model MS125 spectrograph. The emission spectra were typically recorded using an average of twenty laser shots. The gate width, i.e., the exposure time of the $\mathrm{CCD}$, was never more than $5 \%$ of the 60 excited state lifetime.

\section{Results and Discussion}

\section{Electrochemical Properties}

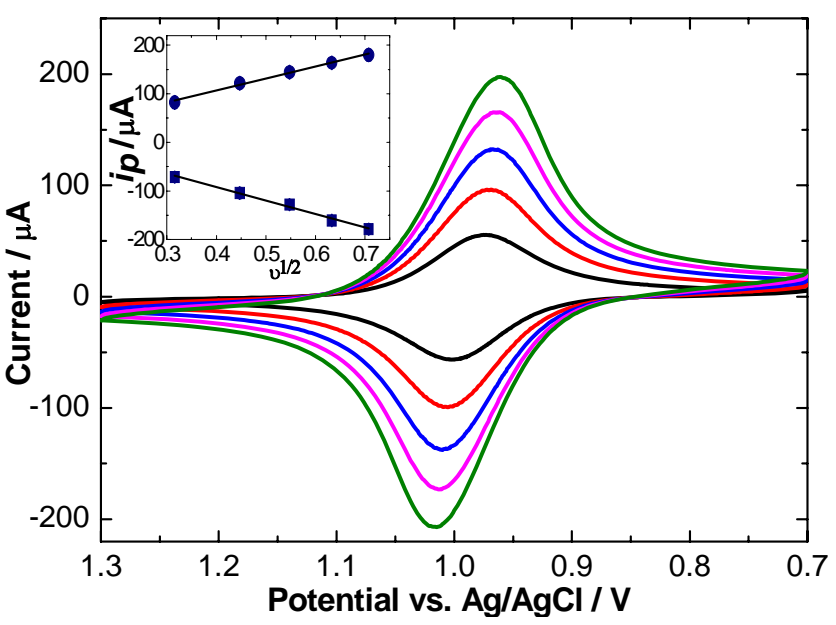

Figure 1. Scan rate dependency for thin films of $\left[\mathrm{Ru}(\mathrm{bpy})_{2}(\mathrm{PPyBBIM})_{10}\right]^{2+},\left(\Gamma=(2.1 \pm 0.2) \times 10^{-8} \mathrm{molcm}^{-2}\right)$, in $0.1 \mathrm{M}$ $\mathrm{LiClO}_{4}, 100<v<500 \mathrm{mVs}^{-1}$. Inset shows the Randles-Sevcik plot for this data. Error data represent triplicate results. Analysis was performed at $\mathrm{pH}$ 6.0 .

Pickup et. al. ${ }^{6}$ first reported on the electrochemical properties of this class of metallopolymer. However, these investigations ${ }_{65}$ did not address the impact of intersite separation on the extent of electronic communication in the ground and excited states. Here, cyclic voltammetry is used to probe the ground state communication between adjacent ruthenium centres as the loading of the ruthenium centres is varied. Figure 1 shows the 70 effect of changing the scan rate, $v$, for $0.1 \leq v \leq 0.5 \mathrm{Vs}^{-1}$ on the cyclic voltammetry of a thin film of $\left[\mathrm{Ru}(\mathrm{bpy})_{2}(\mathrm{PPyBBIM})_{10}\right]^{2+}$, deposited on a glassy carbon electrode, i.e., where adjacent metal centres are separated by an average of 10 monomer units. Similar responses are 75 observed for each metallopolymer investigated. This figure shows an electrochemically reversible response centred at approximately $+1.1 \mathrm{~V}$ associated with the $\mathrm{Ru}^{2+/ 3+}$ couple. Consistent with the behaviour reported by Pickup et. al. for a model monomer and the polymer where ruthenium complexes 80 are bound to all available coordination sites on the polymer backbone, the formal potential depends on the $\mathrm{pH}$ of the contacting electrolyte solution. ${ }^{6,28}$ This dependence arises from protonation induced changes in the electron density of the polymer backbone suggesting that there is significant 85 electronic communication between the metal centres mediated by the conjugated backbone. ${ }^{29}$ 
This issue can be conveniently addressed by determining the homogeneous charge transfer diffusion coefficient, $\mathrm{D}_{\mathrm{CT}}$, of each metallopolymer. The inset of Figure 2 shows that for 0.1 $\leq v \leq 0.5 \mathrm{Vs}^{-1}$, the voltammetric peak currents, $\mathrm{i}_{\mathrm{p}}$, increase as $5 v^{1 / 2}$. This behaviour is consistent with semi-infinite linear diffusion and under these conditions the response can be described by the Randles-Sevçik Equation;

$$
i_{p}=2.65 \times 10^{5} n^{3 / 2} A D_{c t} v^{1 / 2} C
$$

where $n$ is the number of electrons transferred, $A$ is the area of 10 the working electrode, $\mathrm{D}_{\mathrm{CT}}$ is the homogeneous charge transport diffusion coefficient, and $C$ is the concentration of the redox centres. The concentration of ruthenium centres within the metallopolymer has been determined from density measurements in non-swelling solvents as $0.8 \mathrm{M}$. Thus,

${ }_{15}$ Equation 1 allows $D_{C T}$ to be estimated for both the oxidation and reduction processes of each metallopolymer. For the $\left[\mathrm{Ru}(\mathrm{bpy})_{2}(\mathrm{PPyBBIM})_{3}\right]^{2+}$ a $\mathrm{D}_{\mathrm{CT}}$ value of $(3.6 \pm 0.5) \times 10^{-10} \mathrm{~cm}^{2} \mathrm{~s}$ ${ }^{1}$ was observed. The $\mathrm{D}_{\mathrm{CT}}$ values obtained for these polymers are approximately an order of magnitude faster than those 20 obtained for metallopolymers based on non-conjugated backbones such as poly-4-vinylpyridine. ${ }^{17,18,30}$ However given the degree of heterogeneity present within metallopolymer films, the interpretation of the $\mathrm{D}_{\mathrm{CT}}$ may be more complex. Undoubtedly, the greater separation between redox sites in ${ }_{25}\left[\mathrm{Ru}(\mathrm{bpy})_{2}(\mathrm{PPyBBIM})_{20}\right]^{2+}$ is likely to be an important factor in the smaller value of $\mathrm{D}_{\mathrm{CT}}$, but a difference in film structure would also be expected to have a contributory effect, with the more compact nature of the $\left[\mathrm{Ru}(\text { bpy })_{2}(\mathrm{PPyBBIM})_{3}\right]^{2+}$ flims leading to a higher $\mathrm{D}_{\mathrm{CT}}$ value. ${ }^{31}$

30 Table 1. $D_{C T}, D_{e}$ and Conductivity values for $\left[\mathrm{Ru}(\mathrm{bpy})_{2}(\mathrm{PPyBBIM})_{\mathrm{n}}\right]^{2+}$.

\begin{tabular}{cccc}
\hline $\begin{array}{c}\text { Polymer } \\
\text { Loading, } \\
\mathrm{n}\end{array}$ & $D_{C T}\left(\mathrm{~cm}^{2} \mathrm{~S}^{-1}\right)$ & $D_{e}\left(\mathrm{~cm}^{2} \mathrm{~S}^{-1}\right)$ & $\begin{array}{c}\text { Conductivity } \\
\left(\mathrm{Scm}^{-1}\right)\end{array}$ \\
\hline 3 & $3.9 \pm 0.8 \times 10^{-10}$ & $9.1 \pm 0.5 \times 10^{-11}$ & $1.4 \times 10^{-8}$ \\
10 & $4.7 \pm 1.1 \times 10^{-10}$ & $3.4 \pm 0.9 \times 10^{-10}$ & $1.1 \times 10^{-9}$ \\
20 & $7.1 \pm 1.2 \times 10^{-11}$ & $1.6 \pm 1.2 \times 10^{-11}$ & $3.2 \times 10^{-9}$ \\
\hline
\end{tabular}

All values based on averaged results from 5 independent measurements.

There are a number of processes that could limit the rate of homogeneous charge transport through films of this kind, including electron hopping, counterion diffusion/migration or 35 movement of polymer chains or segments to bring adjacent redox centres sufficiently close to allow electron transfer to occur. ${ }^{32}$ Significantly, Table 1 shows that increasing the number of metal centres within the metallopolymer does not result in an exponential increase in the rate of homogeneous 40 charge transport through the film. For example, $\mathrm{D}_{\mathrm{CT}}$ increases from $(7.1 \pm 1.2) \times 10^{-11} \mathrm{~cm}^{2} \mathrm{~s}^{-1}$ to $(4.8 \pm 1.2) \times 10^{-10} \mathrm{~cm}^{2} \mathrm{~s}^{-1}$ as the loading increases from 1 in 20 to 1 in 10 . However, increasing the loading to 1 metal centre per 3 monomer units does not result in an increased $\mathrm{D}_{\mathrm{CT}}$ that might be expected on 45 the basis of a decreased electron transfer distance. These results suggest that charge compensating counterion motion, or segmental polymer chain motion, may influence the rate of charge transport. This possibility has been probed by measuring the electronic conductivity and hence the rate of

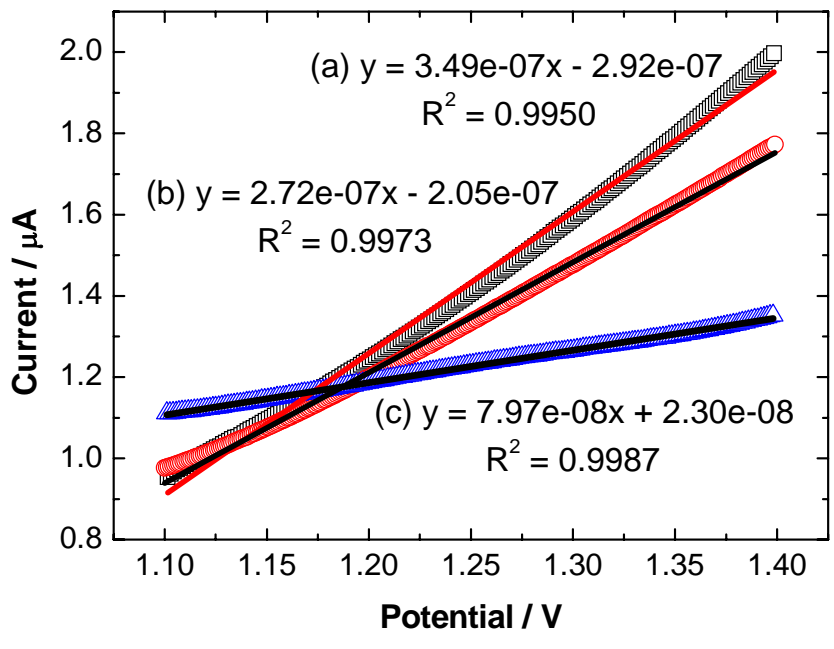

Figure 2. Voltammetric response for thin films of $\left[\mathrm{Ru}(\mathrm{bpy})_{2}(\mathrm{PPyBBIM})_{\mathrm{n}}\right]^{2+}$, where $\mathrm{n}$ is (a, squares) 3, (b, circles) 10 and (c, triangles) is 20 , cycled over the range where $\left[\mathrm{Ru}^{2+}\right] /\left[\mathrm{Ru}^{3+}\right]=1$ on IDAs. The supporting electrolyte was $0.1 \mathrm{M} \mathrm{LiClO}_{4} . \Gamma=7 \times 10^{-8}$ molcm ${ }^{-2}$. Analysis was performed at $\mathrm{pH}$ 6.0.

50 electron diffusion, $\mathrm{D}_{\mathrm{e}}$, using interdigitated array electrodes (IDAs) coated with the metallopolymer. Specifically, as originally demonstrated by Wrighton and co-workers 33,34,35, the film conductivity can be obtained from the slope, $\partial i / \partial E$. Where electron transport is rate limiting, the values of $D_{C T}$ 55 and $\mathrm{D}_{\mathrm{e}}$ will be similar.

Figure 2 shows that the current varies approximately linearly with potential between $+1.1 \mathrm{~V}$ and $+1.4 \mathrm{~V}$ and the slopes can be used in conjunction with Equation 2 below to determine the conductivity, $\sigma$, where $\left(d_{G} / A_{\text {total }}\right)$ is the ${ }_{60}$ Zaretsky cell constant $\left(0.04 \mathrm{~cm}^{-1}\right)$.

$$
\sigma=\mathrm{d}_{\mathrm{G}} \partial \mathrm{i} / \mathrm{A}_{\text {total }} \partial \mathrm{E}
$$

The change of film conductivity has been measured in an ${ }_{65}$ atmosphere of dry $\mathrm{N}_{2}$ at room temperature and pressure. The slopes of the best fit line to the data in Figure 2 yield conductivities between $6.4 \times 10^{-9}$ and $2.3 \times 10^{-8} \mathrm{~S}^{-1} \mathrm{~cm}^{-1}$ depending on the ruthenium loading. A similar trend was also observed over the potential range, $-0.4 \mathrm{~V}$ and $+0.2 \mathrm{~V}$, where 70 no redox chemistry occurs. (This is shown in Figure S1 †ESI).

When electron hopping represents the overall charge transport rate through the metallopolymer film, the DahmsRuff equation ${ }^{36,37}$ can be used to calculate the electron selfexchange rate constant, $k_{S E}$, from the $D_{C T}$ according to 75 Equation 3:

$$
D_{C T}=D_{p h y s}+\frac{1}{6} k_{S E} \delta^{2} C
$$

where $C$ is the concentration of $\mathrm{Ru}$ redox centres within the film, $\delta$ is the intersite separation between adjacent $\mathrm{Ru}$ redox 80 centres, and $D_{\text {phys }}$ describes physical diffusion in the absence of electron hopping. In this situation, $D_{\text {phys }}$ is assumed to be zero, because the $\mathrm{Ru}$ centres are coordinated to the polymer backbone. Therefore, Equation 3 reduces to:

$$
D_{C T}=\frac{1}{6} k_{S E} \delta^{2} C
$$

${ }_{85}$ For a hypothetical cubic lattice $\operatorname{model}^{38,39}$ applied to 
electron transport in redox polymers, the electron selfexchange rate constant, $k_{S E}$, also can be calculated as Equation 5:

$$
k_{S E}=\frac{6 R T \sigma}{10^{-3} F^{2} \delta^{2}[R u]^{2+}[R u]^{3+}}
$$

where $k_{S E}$ is the electron self-exchange rate constant, $R$ is the gas constant, $\sigma$ is the conductivity at temperature $T(K), \mathrm{F}$ is the Faraday constant, and $\delta$ is the intersite separation between adjacent $\mathrm{Ru}$ redox centres. When we combine Equation 4 and 105 , and make the concentration ratio of $[\mathrm{Ru}]^{2+} /[\mathrm{Ru}]^{3+}=1, D_{C T}$ is given by Equation 6:

$$
D_{C T}=\frac{4 R T \sigma}{10^{-3} F^{2} C}
$$

The $\mathrm{D}_{\mathrm{CT}}$ values measured using equation 6 are referred to as $D_{e}$ and shown in Table 1 . These charge transport rates 15 obtained using the IDAs and cyclic voltammetry are consistent with one another to within a factor of three in the worst case. Therefore, these IDA measurements confirm that the movement of charge compensating counterions does not represent the rate determining step for homogeneous charge

20 transport through these films. This result, coupled to the relatively large $\mathrm{D}_{\mathrm{CT}}$ values obtained, suggests that electron transfer, most likely mediated by the conjugated polymer backbone, limits the overall rate of charge transport. It is important to note that the $\mathrm{D}_{\mathrm{CT}}$ values reported here are 25 approximately an order of magnitude smaller than those previously reported ${ }^{6}$ for the polymer when fully loaded with metal centres at $\mathrm{pH}$ 12. This difference is expected since the separation between the ruthenium centres is significantly lower in Pickup's materials and electron density of the 30 polymer backbone ought to be higher in the deprotonated state thus increasing the efficiency of electron transfer. The role of $\mathrm{N}-\mathrm{H}$ reactivity in the ground and excited states, and of the structural dimension (both static and dynamic), could not be performed in this current study. As a consequence, the precise 35 contribution of $\mathrm{N}-\mathrm{H}$ protonation/deprotonation, particularly those directly attached to the ruthenium metal centre and those associated with the benzimidazole moiety, towards charge transport within these metallopolymers could not be quantified. $^{40,41}$ Further investigations requiring the use of 40 density functional theory (DFT) calculations would facilitate this. There would obviously be a higher significance of these contributions when the ratio of the metal centre to the benzimidazole backbone is high.

\section{Effect of Metal Loading on the Steady State Luminescence}

${ }_{45}$ Figure 3 shows UV-Vis absorption and luminescence spectra for the metallopolymer backbone. This figure shows that the polymer backbone emits at approximately $480 \mathrm{~nm}$ and has a Stokes shift of approximately $70 \mathrm{~nm}$. This figure also shows that the emission spectrum obtained for the 1:10 50 metallopolymer shows two peaks at approximately 500 and $670 \mathrm{~nm}$. The emission observed at $500 \mathrm{~nm}$ is assigned to the poly[2-(2-pyridyl)-bibenzimidazole] polymer backbone while the $670 \mathrm{~nm}$ emission is attributed to the ruthenium metal centre. This observation of dual emission is important since 55 according to Kasha's Rule ${ }^{42}$ emission should only be observed from the lower energy ruthenium based excited state if energy

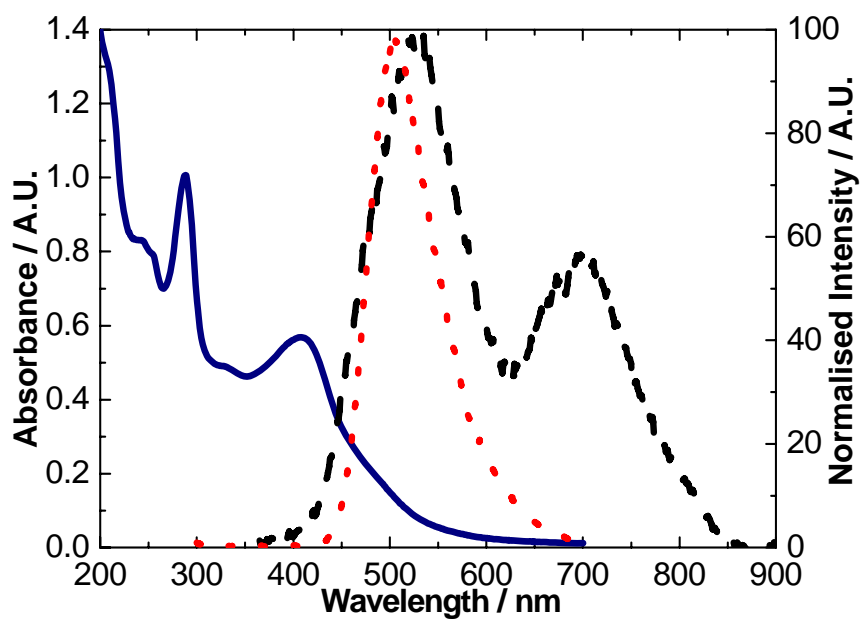

Figure 3. Overlapping $\left[\mathrm{Ru}(\mathrm{bpy})_{2}(\mathrm{PPyBBIM})_{3}\right]^{2+}$ absorption (solid line), (PPyBBIM) emission (dotted line) and $\left[\mathrm{Ru}(\mathrm{bpy})_{2}(\mathrm{PPyBBIM})_{3}\right]^{2+}$ emission spectra (dashed line). All spectra were measured in $100 \mu \mathrm{M}$ degassed acetonitrile solutions at $298 \mathrm{~K}$.

or excited state electron transfer is possible. ${ }^{43,44}$ Significantly, Figure 3 shows that while there is spectral overlap between the emission spectrum of the benzimidazole polymer ${ }_{60}$ backbone and the ruthenium based absorbance this does not lead to emission exclusively from the ruthenium centres. The electrochemical investigations discussed above reveal that there is significant electronic communication between the ruthenium centres in the ground state. A key issue is the 65 extent to which excited state electron transfer can occur in this metallopolymer.

An estimation of the thermodynamic driving force for excited state electron transfer allows the most energetically favourable process to be identified:

70

$$
\Delta G^{0}=\left\lfloor E^{0}(\text { Donor })-E^{0}(\text { Acceptor })\right]
$$

The Rehm-Weller equation ${ }^{45}$ approach can be used to estimate the excited state oxidation, $\mathrm{E}^{0 *}{ }_{\mathrm{ox}}$, and reduction potentials, $\mathrm{E}^{0^{*}}$ Red :

$$
\begin{aligned}
& E_{O x}^{0^{*}}=E_{O x}^{0}-E^{00} \\
& E_{\operatorname{Re} d}^{0^{*}}=E_{\operatorname{Re} d}^{0}+E^{00}
\end{aligned}
$$

where $\mathrm{E}_{\mathrm{Ox}}^{\mathrm{o}}$ and $\mathrm{E}_{\text {Red }}^{\mathrm{o}}$ are the formal potentials associated with the first oxidation and reduction of the metal centre or polymer in the ground state. $\mathrm{E}^{00}$ is the energy difference between the lowest vibrational levels of the ground and 80 excited states and has been estimated from the wavelength of maximum emission at $77 \mathrm{~K}$.

For the imidazole based polymer backbone, the emission at $77 \mathrm{~K}$ is $516 \mathrm{~nm}$ corresponding to an $\mathrm{E}^{00}$ value of $2.4 \mathrm{eV}$. $(77 \mathrm{~K}$ emission spectra is given in $† \mathrm{ESI})$. As previously discussed, 85 no polymer based oxidation processes are observed for potentials up to $+1.400 \mathrm{~V}$ while the $\mathrm{E}_{\text {Red }}^{\mathrm{o}}$ of the backbone is $0.7 \mathrm{~V}$. Therefore, using Equation 3.7, the $\mathrm{E}_{\mathrm{Ox}}^{\mathrm{o}}{ }^{*}$ for the polymer is estimated to be $-1.0 \mathrm{~V}$. For the ruthenium centres, solution phase cyclic voltammetry indicates that $\mathrm{E}^{\mathrm{O}^{*}} \mathrm{Ox}$ and ${ }_{90} \mathrm{E}^{\mathrm{o}^{*}}$ Red $\left(\right.$ metal based $\mathrm{Ru}^{2+/ 3+}$ ) are -0.8 and +0.8 respectively.

Equation 7 reveals that electron transfer from the polymer excited state to the ruthenium is endergonic by at least $0.2 \mathrm{eV}$, 
$(\Delta \mathrm{E}=(-1.0 \mathrm{eV}-(-1.2 \mathrm{eV}))$. Electron transfer from the excited state ruthenium to the polymer is exergonic by approximately $0.1 \mathrm{eV}(\Delta \mathrm{E}=(-0.8 \mathrm{eV}-(-0.7 \mathrm{eV}))$. Therefore, while a modest driving force exists for photoinduced electron 5 transfer from the metal centres to the polymer backbone, excited state electron transfer from the polymer to the ruthenium centres is thermodynamically uphill. Thus, it appears that the Forster overlap between the polymer backbone and the ruthenium centres and a weak driving force 10 for photoinduced electron transfer allows both the polymer backbone and the ruthenium centres to emit.

A key advantage of these metallopolymers is that the loading of ruthenium centres can be systematically varied so as to change the intersite separation. Figures 4 and 5 illustrate 15 the dependence of the emission spectra on the ruthenium loading following excitation at $355 \mathrm{~nm}$ (excitation of both polymer backbone and ruthenium centres) and $450 \mathrm{~nm}$ (predominantly photoexcitation of ruthenium centres), respectively. The relative intensities of the polymer and

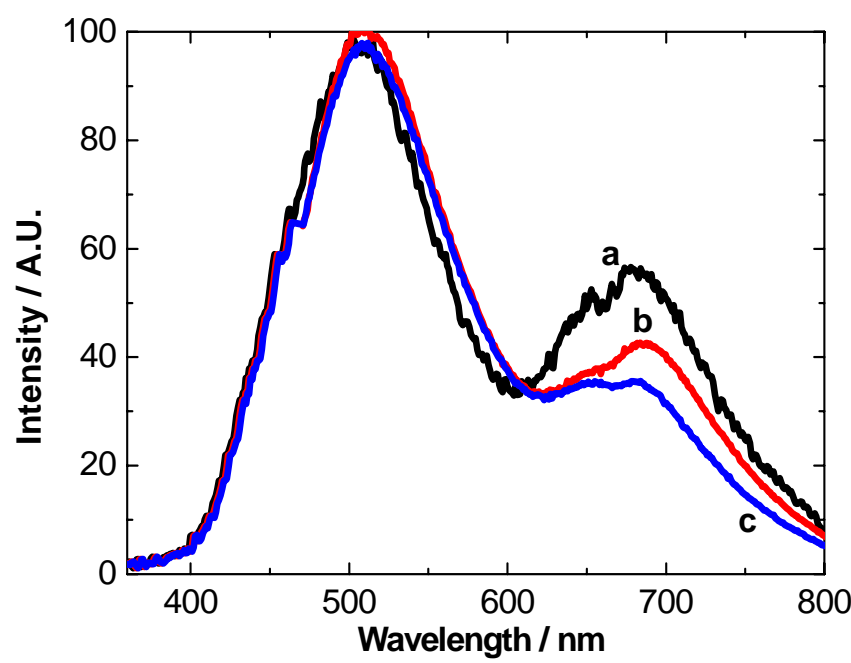

Figure 4. Typical emission spectra for $100 \mu \mathrm{M}\left[\mathrm{Ru}(\mathrm{bpy})_{2}(\mathrm{PPyBBIM})_{\mathrm{n}}\right]^{2+}$ solutions measured in acetonitrile at 298 K. $n=3$ (b), 10 (a) or 20 (c). Excitation wavelength of $355 \mathrm{~nm}$ was utilised. Samples have been absorption matched at the excitation wavelength.

20 ruthenium based emission processes depend on the excitation wavelength which is expected on the basis of the absorption spectra shown in Figure 2. More significantly, irrespective of the excitation wavelength, Figures 4 and 5 show that the metallopolymer with the highest loading of ruthenium centres ${ }_{25}$ does not produce the most intense ruthenium based emission. This behaviour most likely arises because electron transfer from the $\mathrm{Ru}^{2+*}$ species to the polymer backbone (exergonic by approximately $0.1 \mathrm{eV}$ ) becomes more efficient as the intersite separation is reduced leading to partial quenching of the 30 ruthenium emission.
Table 2. Luminescence Lifetimes for $\left[\mathrm{Ru}(\mathrm{bpy})_{2}(\mathrm{PPyBBIM})_{\mathrm{n}}\right]^{2+}$ metallopolymer, (100 $\mu \mathrm{M}$ concentration)

\begin{tabular}{ccc}
\hline $\begin{array}{c}\text { Polymer } \\
\text { Loading }\end{array}$ & $\begin{array}{c}\text { Ruthenium based } \\
\text { emission } \\
(\mathrm{ns})\end{array}$ & $\begin{array}{c}\text { PPyBBIM based } \\
\text { emission } \\
(\mathrm{ns})\end{array}$ \\
\hline $1 / 3$ & $112 \pm 11$ & $33 \pm 6$ \\
$1 / 10$ & $126 \pm 21$ & $36 \pm 5$ \\
$1 / 20$ & $115 \pm 13$ & $32 \pm 7$ \\
\hline
\end{tabular}

Decays monitored at $614 \mathrm{~nm}$ following a $10 \mathrm{~ns}$ laser pulse of $355 \mathrm{~nm}$ excitation. All values based on averaged results from spectra of 5 35 analogous samples.

\section{Luminescence Lifetimes of the Metallopolymers}

The excited state lifetime can provide useful insights into the interactions between the metal centre of the metallopolymer and the PPyBBIM backbone. The emission intensity of the 40 ruthenium free polymer backbone exhibits a single exponential decay following excitation at $355 \mathrm{~nm}$ with an

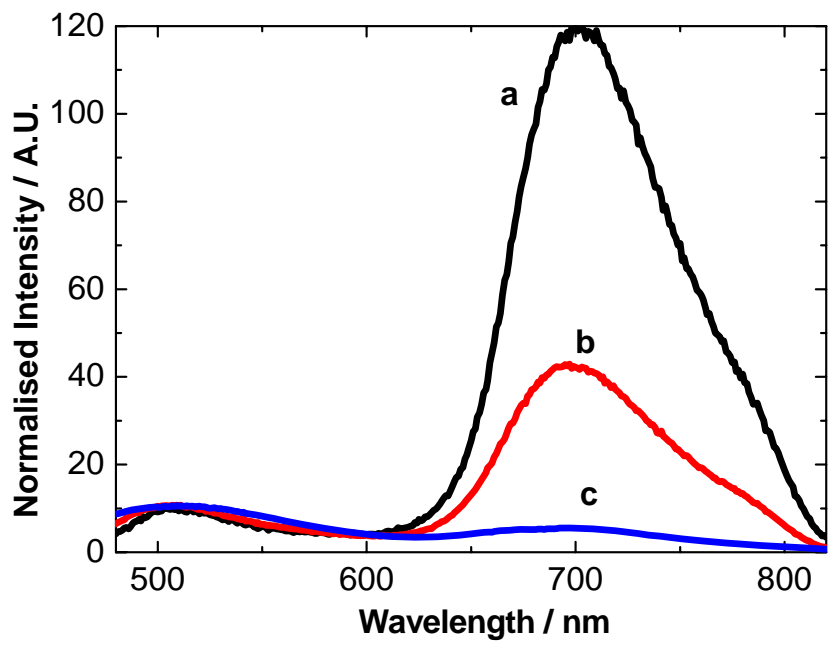

Figure 5. Typical emission spectra for $100 \mu \mathrm{M}\left[\mathrm{Ru}(\mathrm{bpy})_{2}(\mathrm{PPyBBIM})_{\mathrm{n}}\right]^{2+}$ solutions measured in acetonitrile at 298 K. $\mathrm{n}=3$ (b), 10 (a) or 20 (c). Excitation wavelength of $450 \mathrm{~nm}$ was utilised. Samples have been absorption matched at excitation wavelength.

excited state lifetime of $42 \pm 3$ ns. In contrast, the emission of the metallopolymer dissolved in solution following excitation at $355 \mathrm{~nm}$ exhibits a complex decay characterized by at least 45 two time constants. This behaviour is expected due to the dual emission observed from the emission spectra, namely the PPyBBIM backbone and the ruthenium centre. The decays were fitted to a dual exponential decay model to give two limiting excited state lifetimes of approximately 120 and 35 $50 \mathrm{~ns}$. By comparison with the parent polymer, the shorter lifetime is attributed to the polymer backbone emission. Table 2 shows that the emission lifetimes of the ruthenium centres and polymer backbone are insensitive to the metal loading. However, consistent with the intensity based data, the 55 relative contribution to the emission from the ruthenium centres is higher for $\mathrm{n}=10$ than $\mathrm{n}=20$. In contrast, consistent with quenching, the percentage contribution from the ruthenium emission decreases by approximately $30 \%$ on going from the $\mathrm{n}=10$ to $\mathrm{n}=3$ system. 


\section{Conclusions}

Poly[2-(2-pyridyl)-bibenzimidazole] containing ruthenium bis-bipyridyl complexes at controlled intersite separations offer the possibility of combining an electronic $\pi$-conjugated 5 polymer with highly luminescent metal centre. Photophysical and electrochemical measurements reveal significant differences in the extent of electronic communication in the ground and electronic excited states. Significantly, cyclic voltammetry reveals that the rate of homogeneous charge 10 transport, $\mathrm{D}_{\mathrm{CT}}$, associated with charge transfer between adjacent ruthenium centres is approximately an order of magnitude higher than is found for non conjugated metallopolymers. Significantly, electron transfer rather than ion or polymer chain movement represents the rate 15 determining step. Also, the magnitude of $\mathrm{D}_{\mathrm{CT}}$ is directly related to the relative concentration of ruthenium metal centres within the film. However, despite the decreased intersite separation, $\mathrm{D}_{\mathrm{CT}}$ does not increase appreciably on going from $n=10$ to $n=3$.

20 Significantly, the metallopolymers exhibit poor excited state communication with emission being observed from both the polymer backbone and the ruthenium centres. The emission spectra for the polymer backbone and the ruthenium absorbance overlap suggesting that energy transfer ought to

25 occur. Cyclic voltammetry and low temperature emission reveal that electron transfer from the excited state of the polymer to ground state ruthenium centres is thermodynamically uphill but that electron transfer from ruthenium to the polymer backbone is mildly favoured. These

30 two effects result in the maximum emission intensity from the metal centres being observed for the $\mathrm{n}=10$ system rather than from the more heavily labelled $n=3$ system. In conclusion, this work demonstrates that there is an effective trade off between maximum charge transfer rates and maximum 35 luminescence which must be considered if metallopolymers of this type are to be applied to sensor development.

\section{Acknowledgements}

The financial support of Science Foundation Ireland under the Biomedical Diagnostics Institute (Award No. 03/IN3/B402) is 40 deeply appreciated. LD appreciates funding support from the Marie Curie Reintegration Grant (PIRG-2010-268236).

\section{Notes and references}

${ }^{\dagger}$ Centre for Forensic Science, Department of Pure \& Applied Chemistry, University of Strathclyde, Royal College, 204 George Street, Glasgow, 45 G1 1XW, Scotland, UK. Fax: +141 548 2532; Tel: +141 548 4322; Email:lynn.dennany@strath.ac.uk

National Centre for Sensor Research, School of Chemical Sciences, Dublin City University, Dublin 9, Ireland. Fax: +353 1 7005503; Tel: +35317005943; Email:Robert.Forster@dcu.ie

$\dagger$ Electronic Supplementary Information (ESI) available: [Fitting Profile of cyclic voltammogram for $\left[\mathrm{Ru}(\mathrm{bpy})_{2}(\mathrm{PPyBBIM})_{10}\right]^{2+}$ thin films, emission spectra at $77 \mathrm{~K}$ for $\left[\mathrm{Ru}(\mathrm{bpy})_{2}(\mathrm{PPyBBIM})_{10}\right]^{2+}$ and luminescence decay for same are given here]. See DOI: 10.1039/b000000x/

55

1 F.E. Jr. Arnold and F.E. Arnold, Adv. Poly. Sci. 1994, 117, 257.

2 H. Vogel and C.S. Marvel, J. Poly. Sci. 1961, L, 511.
3 A. Techagumpuch, H.S. Nalwa, and S. Miyata, Promising Applications of Conducting Polymers. In Electroresponsive Molecular and Polymeric Systems, Vol. 2; Marcel Dekker: New York, 1988.

4 J.A. Osaheni and S.A. Jenekhe, Chem. Mater. 1992, 4, 1282.

5 M.F. Roberts and S.A. Jenekhe, Chem. Mater. 1994, 6, 135.

6 C.G. Cameron and P.G. Pickup, J. Am. Chem. Soc. 1999, 121, 11773.

7 R.J. Mortimer, Electrochimica Acta. 1999, 44, 2971.

8 B.J. Holiday and T.M. Swager, Chem.Comm. 2005, 1, 23.

9 R.P. Kingsborough and T.M. Swager, Prog. Inorg. Chem. 1999, 48, 123.

10 H. Nishihara, M. Kurashina and M. Murata, Macromol. Symp. 2003, 196, 27.

11 M. Kurashina, T. Wantanabe and H. Nishihara, J. Am. Chem. Soc. 2003, 125, 10345 .

12 S.S. Zhu and T.M. Swager, Adv. Mater. 1996, 8, 497.

13 R.J. Forster and J.G. Vos, J. Chem. Soc. Faraday Trans, 1991, 87, 1863.

14 A.P. Doherty, R.J. Forster, M.R. Smyth and J.G. Vos, Anal. Chim. Acta, 1991, 255, 45.

15 C.H. Lyons, J. Abbas, K. Lee and M.F. Rubner, J. Electroanal. Chem. 1998, 120, 12100.

16 L. Dennany, G.G. Wallace and R.J. Forster, Langmuir, 2010, 25, 14053.

17 L. Dennany, E.J. O’Reilly, P.C. Innis, G.G. Wallace and R.J. Forster, Electrochimica Acta, 2008, 53, 4599.

18 L. Dennany, P.C. Innis, G.G. Wallace and R.J. Forster, J. Phys. Chem. B, 2008, 112, 12907.

19 S. Shardon-Noblat, A. Deronzier, R. Ziessel and D. Zsoldos J. Electroanal. Chem. 1998, 444, 253.

20 O. Haas, M. Kriens and J.G. Vos, J. Am. Chem. Soc. 1981, 103, 1318

21 D.M. Kelly and J.G. Vos, Electroactive Polymer Chemistry, Part 2: Methods and Applications, Lyons, M. (Ed); Plenum Press, New York, 1996, Ch.8.

22 R. Ziessel, Advances in Chemical Conversions for Mittigating Carbon Dioxide, 1998, 114, 219.

23 L. Dennany, T.E. Keyes and R.J. Forster, The Analyst, 2008, 133, 753.

24 A. Venkatanarayanan, A.-M. Spehar-Délèze, L. Dennany, Y Pellegrin, T.E. Keyes and R.J. Forster, Langmuir, 2008, 24, 1123

25 L. Dennany, E.J. O'Reilly, T.E. Keyes and R.J. Forster, Electrochem Comm. 2006, 8, 10. 1588.

26 L. Dennany, R.J. Forster and J.F. Rusling, J. Am. Chem. Soc. 2003, 125, 5213.

27 M. Kaneko, Prog. Polym. Sci. 2006, 26. 1101.

28 C.G. Cameron and P.G. Pickup, J. Am. Chem. Soc. 1999, 121, 7710.

29 B.J. McClean and P.J. Pickup, J. Phys. Chem. B. 2002, 106, 4658.

30 C.F. Hogan and R.J. Forster, Anal. Chim. Acta, 1999, 396 (1), 13.

31 A.P. O’Mullane, J.V. Macpherson, P.R. Unwin, J. CerveraMontesinos, J.A. Manzanares, F. Frehill and J.G. Vos, J. Phys. Chem. $B, 2004$ 108, 7219.

32 R.J. Forster and J.G. Vos, Comprehensive Analytical Chemistry, Ed. G. Svehla, Elsevier, Amsterdam, 1992, vol. XXVII, p. 465.

33 E.W. Paul, A.J. Ricco and M.S. Wrighton, J. Phys. Chem. 1985, 89, 1441 .

34 J.W. Thackeray, H.S. White, and M.S. Wrighton, J. Phys. Chem. 1985, 89, 5133.

35 D. Ofer, R.M. Crooks and M.S. Wrighton, J. Am. Chem. Soc. 1990, 112, 7869.

36 H. Dahms, J. Phys. Chem. 1968, 72, 362.

37 I. Ruff, V.J. Friedrich, K. Demeter and K. Csillag, J. Phys. Chem. 1978, 75, 3303.

38 R.H. Terrill, J.E. Hutchinson and R.W. Murray, J. Phys. Chem. B, 1997, 101, 1535.

39 W.P. Wuelfing, S.J. Green, J.J. Pietron, D.E. Cliffel and R.W. Murray, J. Am. Chem. Soc. 2000, 122, 11465.

40 P. Crawford and P. Hu, J. Phys. Chem. B, 2006, 110, 4157. 
41 Y.-M. Xing, X.-F. Xu, Z.-S. Cai and X.-X. Zhao, J. Mol. Structure, 2004, 671, 27.

42 M. Kasha, Discuss. Faraday Soc. 1950, 9, 14

43 T.E. Keyes, C. O’Connor and J.G. Vos, Chem. Commun. 1998, 889

44 M.R. Blakely and K.M. DeArmond, J. Am. Chem. Soc. 1987, 109, 4895.

45 D. Rehm and A. Weller, Israel J. Chem., 1970, 8, 259. 